\title{
Architectural building design with refurbished shipping containers: A typological and modular approach
}

\author{
Luiz António Pereira-de-Oliveira, Luís Filipe Almeida Bernardo* and Ana Raquel Araújo \\ Marques \\ C-MADE - Centre of Materials and Building Technologies, Department of Civil Engineering and Architecture, University of Beira Interior, \\ 6201-001 Covilhã, Portugal \\ *Corresponding Author: lfb@ubi.pt
}

Submitted : 13/06/2020

Revised :30/06/2021

Accepted :24/07/2021

\begin{abstract}
Construction of housing buildings using refurbished shipping containers constitutes a successful recent building system. As construction modules, disposed and recycled containers are considered to contribute for a sustainable construction system. This article aims to contribute to a better understanding of this construction system, in particular, the architectural project. A methodology based on the typological and modular coordination is proposed as a key tool to help with the development of spatial arrangements by considering the shipping container as a unit/module. The functional occupation typologies were proposed to characterize the main housing activities to be considered in modular coordinated design, allowing to adapt the housing to the family needs according to their social and cultural dynamics. The module constitution and geometry considering two commercial maritime shipping containers are presented.
\end{abstract}

Keywords: Architectural design; Construction system; Modular coordination, Occupation typology; Shipping container.

\section{INTRODUCTION}

Over the past years, a significant slowdown in the maritime transportation flow has been observed as a result of the global economic crisis. Consequently, the number of empty shipping containers parked in seaports, mainly in importing countries, has increased. This situation has led to problems associated with space allocation in seaports (Pisinger, 2002; Santisi, 2010). These problems strongly contributed to finding new market niches for shipping containers disposed of beside the main function for which these elements were designed, which is transportation and storage of goods. One of the most promising market niches is the construction of housing buildings using containers.

Robinson and Swindells (2012) argued that one of the major disadvantages associated with a container building is its uncompromising aesthetics, which results from the steel-box looking feature, looking more like a product to maximize the function rather than a building. However, if the units of containers are combined, arranged, and 
creatively composed as a whole building, it can have a huge potential to be a unique and outstanding architectural feature (Brandt, 2011).

One of the major advantages of a container building is the possibility of being easily moved or transported from one site to another in shorter time. Due to this advantage, container buildings have always been used as site office, emergency housing, or even as mobile clinic (Christensen and Worzala, 2010). In fact, several reasons justify the use of shipping container as a constructive system for buildings, namely:

- The modular characteristics of containers allow easy conjugation of these elements to form aesthetics architectural compositions as needed (Ismail et al., 2015);

- Containers are easily transportable (Ismail et al., 2015);

- Containers are very resistant to high loads and aggressive environments (Silva, 2010; Lourenço, 2010; Giriunas et al., 2012; Bernardo et al., 2013);

- Containers can easily be adapted and equipped with many infrastructures and systems for habitability (Nunes, 2009).

The constructive flexibility, structural safety, and possibility of immediate use of containers after being conveyed to the final destination support the idea of a highly nomadic construction. Furthermore, sustainability in construction is nowadays an important topic due to the environmental impact that building materials cause throughout their supply chain. It is today recognized that the rationalization and innovation of construction are urgent (European Commission, 2007). This rationalization is only possible if a higher level of efficiency in use of already available resources is achieved. Based on the reasons presented previously, the construction of housing buildings with refurbished shipping containers constitutes an interesting and sustainable construction system, which can contribute to avoid loss of energy and natural resources, namely, the energy needed for the production of steel for construction (Vijayalaxmi, 2010; Lun, 2011). Several housing buildings, as well as service buildings, constructed with refurbished shipping containers exist all over the world for over a decade (Webb, 2006; Slessor, 2007; Murdock, 2009). Several of these successful examples can be found in architectural literature and websites, showing the feasibility of this building system. Notwithstanding, the construction of a green building is not simply a matter of assembling a collection of cutting-edge green technologies or materials; it is rather a process that firstly involves the optimization of design elements (Ahmad et al., 2016). In this sense, the goal of a container refurbished project could be harmonized through a design scheme, viewed as an assembly of many subsystems and subsolutions that are suggested by precedent-based knowledge models, which offer basic vocabulary or templates for designers to follow and to develop new alternatives (Eilouti, 2009). In terms of demand for energy or other resources, the main geometric feature of containers is their compactness. This feature can be associated with the problem of efficient use of the whole external enclosure elements of a building. It has been found that the geometric efficiency of a building both depends on its size and proportions (Parasonis et al., 2012). In fact, the selection of the architectural form composition is one of the most important tasks of architects. Form composition is not only applied for organizing different spaces in architectural design. Choosing the type of form composition plays also an important role in decreasing the vulnerability and increasing the safety of the building, since it influences the structural performance of the building, which needs to be checked by the structural engineer (Bernardo et al., 2013; Bitarafan et al., 2015).

Volker et al. (2008) state that materials, scale, and shape of the building require a careful study to improve the design quality to be achieved. Based on these factors, the designer can restructure a primary shape based on its interpretation and on recognizing emergent subshapes, enabling the design of better spatial arrangements.

In connection with the key ideas previously presented, the modular coordination theory can constitute an important tool to help the architect design spatial arrangements, which contribute to construction sustainability. By using modular coordination, in which the shipping container is considered as a unit/module, it is possible to rationalize the use of resources and also avoid wastes. Through the recycling of disposed shipping containers or containers at 
end of life, and by using modular coordination in the architectural design stage, it is possible to, simultaneously, reach an efficient and sustainable architectural solution.

Among several types of containers existing in the market, containers manufactured in accordance with ISO standards (ISO 1496-1, 1990; ISO 668, 1995; ISO 3874 1997; ISO 830, 1999) are of special interest, because such elements ensure uniformity for the geometrical and mechanical properties. For construction, these requirements are very important. The most common ISO shipping containers in the market have lengths in the range of 3.0-12.0 m and heights in the range of 2.4-2.7 m. For housing buildings, containers with $6.0 \mathrm{~m}$ and $12.0 \mathrm{~m}$ long, and $2.7 \mathrm{~m}$ high, are of special interest, because they provide interesting areas and sufficient ceiling height. Such containers are called High Cube (HC) and have the following commercial denominations: $20^{\prime} \mathrm{HC}$ (with $6.0 \mathrm{~m}=20$ feet long) and $40^{\prime} \mathrm{HC}$ (with $12.0 \mathrm{~m}=40$ feet long).

Shipping containers are essentially made of steel. They incorporate steel trapezoidal sheets to form the walls and the roof, as well as steel profiles to form the edges of the "box" and the grid to support the wooden floor. The doors are composed with steel profiles and steel sheets. The corners of the "box" incorporate stiffer steel pieces to support the containers and to allow for the connection between containers.

As previously explained, shipping containers are designed to carry very high loads, as well as to resist aggressive environments during a lifetime of at least 15 years (ISBU, 2009; Giriunas et al., 2012; Bernardo et al., 2013). These requirements (resistance and durability) are very important since, in constructions using containers, these elements are usually used as the main structure.

Finally, international technical papers focused on the construction of housing buildings using refurbished containers are still scarce. Most of the existing literature mainly presents successful study cases and mainly focuses the general architectural aspects. This paper aims to contribute to a better knowledge of this construction system for the architectural project. Based on a research work performed at the University of Beira Interior (Marques, 2011), a general methodology based on the typological occupation and modular coordination is presented as a key tool to help for the development of spatial arrangements by considering the shipping container as a unit/module.

\section{FUNDAMENTAL PRINCIPLES OF MODULAR COORDINATION}

In architecture, the module is used as a measurement unit originally based in a classical interpretation of the aesthetic nature from the Greeks (Baldauf, 2004). For the Greeks, the module was the regulator measurement in order to achieve harmony and proportions between the several building elements. Their dimensional basic unit was the diameter of the column from which all dimensions were created. The Romans adopted an aesthetic and functional base-module to ensure harmony and proportions of constructions, based on anthropometric measurements system (for instance, legs, arms, etc.).

In mid-eighteenth century, the first application of modular coordination came from the industrial revolution. For the construction of the Crystal Palace by Joseph Paxton in 1850/1851, a rigorous and detailed study was performed for all construction elements, production methods, mounting systems, and construction schedules, under a strict cost control. The construction element, which affected the choice of the module, was based on the glass construction elements with 8-feet maximum size. This dimension determined the mesh size to apply the modular coordination methodology.

In 1921, Le Corbusier stated that houses should be mass-produced in factories. In 1930, Alfred Farwell Bemis proposed, in his book "The Evolving House," a coordination technique known as "cubic modular method." Bemis 
proposed that the building components should be mass-produced and composed by cubic modules to form the threedimensional building.

In general, it can be stated that modular coordination aims to rationalize the construction by following technical standards and an efficient certification system; that is, building components undergo a dimensional pattern. Thus, building components show similar dimensional characteristics with less variety of typologies. Although the components can be produced in different factories, they are compatible since they respect a dimensional pattern.

The standardization of building components contributes to simplify the project and the construction steps, because the most common constructive details are solved according to the standardization. Construction consists on typified assembly, because standardized components can be assembled without additional works (for instance, cutting), which also contributes to reduce wastes. Modular coordination also contributes to reduce the consumption of raw materials, because the use of the materials is optimized.

Modular coordination is based on three fundamental principles: the reference system, the module, and the modular setting. According to Zechmeister (2005), the aim of the reference system is to position each building component in space. Since the module constitutes the basic unit of measurement, the modular setting establishes the connection between the building components and the reference system.

\section{The Reference System}

As an example, according to NBR 5731 standard (1982) from the Brazilian Association of Technical Standards (ABNT), the reference system is composed by a system of planes parallel to three orthogonal planes. These planes define the so-called axonometric trihedron (Fig. 1(a)). With this reference system, the position of each point in space is defined from its projections in the referred planes. This system allows to define 2- or 3-dimensional modular reference grids, which can be used as references to position the construction elements (Fig. 1(b) and Fig. 1(c)).

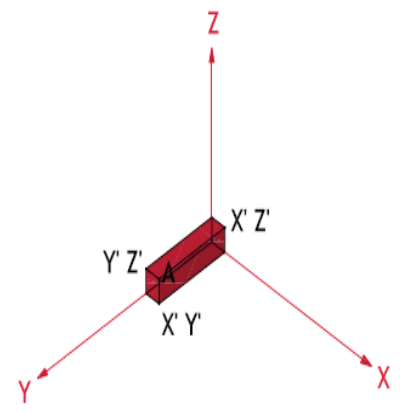

(a)

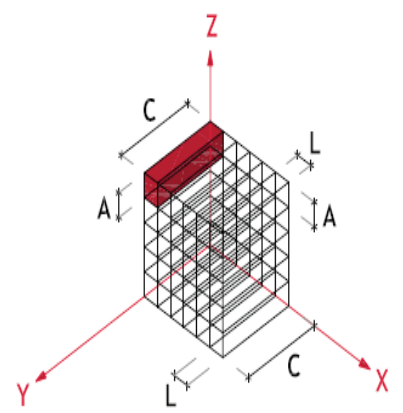

(b)

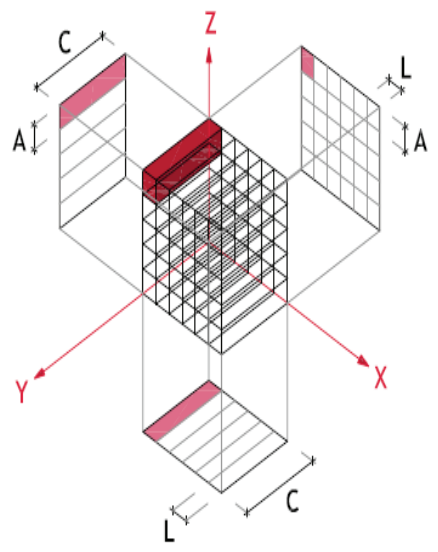

(c)

Figure 1. Axonometric trihedron and spatial meshes for a module based on the shipping container 40 'HC.

The 2-dimensional modular reference grid is defined by the intersection lines of a system of planes spaced with a distance equal to the module size and parallel to three and two-by-two orthogonal planes. The 3-dimensional modular reference grids are defined from the orthogonal projection of the spatial reference grid into a plane parallel to one of the three orthogonal planes. The spacing of the mesh lines is defined by the module size. 


\section{The Module}

The module represents the distance between two consecutive planes in the system, which leads to the spatial modular reference grid. This distance depends on the base-size of the building components. In this article, the dimension of shipping containers $\left(40^{\prime} \mathrm{HC}\right.$ and $\left.20^{\prime} \mathrm{HC}\right)$ will be used to define the module (Figure 2).

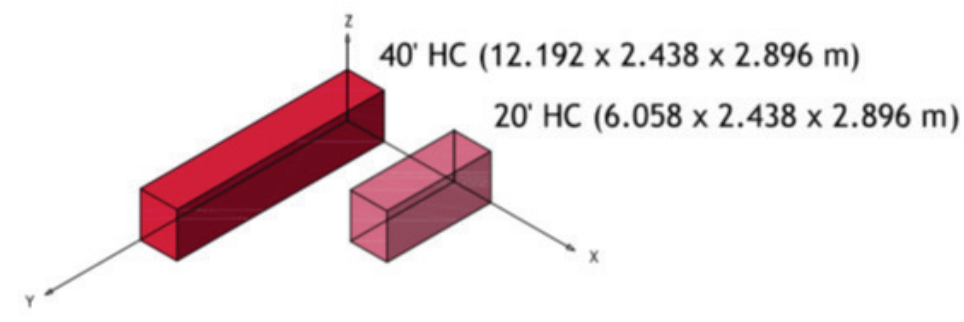

Figure 2. Dimensional modules based on shipping container size ( $40^{\prime} \mathrm{HC}$ and $\left.20^{\prime} \mathrm{HC}\right)$.

\section{The Modular Setting}

The modular setting must be based on the spatial modular reference grid previously defined. All project drawings of the building components are developed on the reference grid. This allows for a simplified representation of the assemblage of the building components.

The multimodular reference grid is the one composed with lines with spacing equal to the multimodule. For instance, according to NBR 5731 (1982), this last one is obtained from the product of an integer with the base-module. Using the multimodule allows to reduce the number of measurements used in modular coordination. The multimodules can be divided into horizontal (referred to as the horizontal dimensional modular reference grid) and vertical (referred to as the vertical dimensional modular reference grid), as illustrated in Fig. 3(a). From the module, submodules can also be defined, as illustrated in Fig. 3(b). According to NBR 5731 (1982), the submodule (sM) represents a fraction of the module. This fraction is given by $n M / 4$, where $n$ is any positive integer, and $M$ is the module. Submodules can be used for building components with lesser dimensions than the basic-module (Baldauf, 2004).

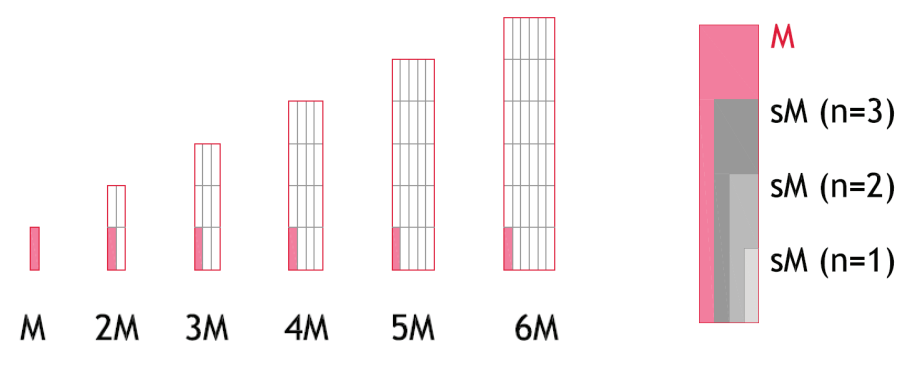

(a)

(b)

Figure 3. Module M (container 40' HC), multimodules (2M to $6 \mathrm{M}$ ), and submodules (sM). 


\section{STUDY AND APPLICATION OF THE SPATIAL ARRANGEMENTS WITH SHIPPING CONTAINERS}

This study aims to show the possible spatial arrangements of shipping containers, which contribute for the sustainability of buildings, considering the requirements of habitability and conformation of architectural spaces. For this purpose, the concept of "living" in a house must be firstly clarified, as well as other associated concepts. These clarifications are important to analyze the direct influence of these concepts on the container modulation.

The concept of "living" in a house is related with the satisfaction of a set of humans, with individual and collective needs. Such needs meet in two sociospatial levels: housing and habitat (Figure 4). Housing encompasses the accommodation itself, while the habitat is the surrounding environment of the housing with physical, social, and functional significance.

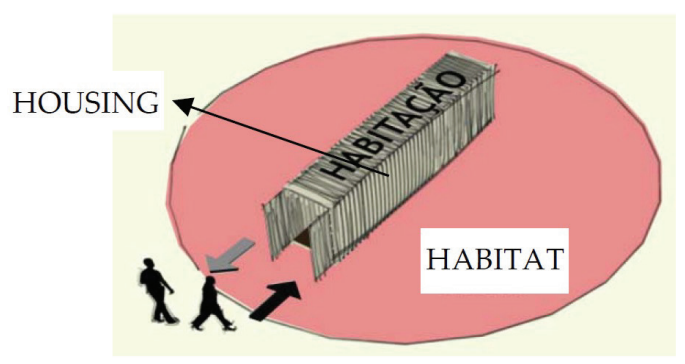

Figure 4. Housing and habitat concepts.

Castelo (2008) stated that "living" is fully achieved if it provides to the individual the delimitation of a built space (housing), which ensures:

- security: shelter and protection;

- privacy: intimacy, isolation, independence, etc.;

- dissatisfactions compensations (from labor, environment, etc.);

- to establish a "subject-object" dialectic relationship (between "living" and housing);

- to perform the desired image of the territorial space;

- to express a well-defined territoriality (individual and household), physically and psychologically delimitated;

- to affirm itself, through land management, spaces, and objects.

The result of all these factors is the definition of individuality, which is dependent on the housing/habitat relationship. The habitat should be an extension of the housing, a system of social interactions related to it, rather than an undifferentiated urban space (Figure 4).

The housing is a built formalization (physical), a rational set of articulated spaces with a sufficient area able to meet the specific needs of use of the individual and household.

The functional issue of housing is related, in part, to the accommodation, and even more with the outer aspects, quality of habitat and urban life. Once the individual or group life has become more diverse and complex, the family structure is presented itself as multifaceted and requires specific attention from the architect. For this, it is necessary to analyze the daily behaviors of the family, alone or accompanied by other people, as well as the relations and phenomena such as private/public, work/leisure, or youth/adults. 
This functional analysis of housing is useful to discuss the use and appropriation of space in general, to define typologies of occupancy as required, to suit the housing to the family needs, or even to analyze ergonomically the use of certain spaces and compartments.

The housing program is defined through a survey about the functions of use of the housing to allow flexibility in the composition of the compartments, being possible to organize them according to the point of view of the dwellers. This survey facilitates the architectural design and allows to know the requirements of each functional area, which constitutes the housing. Table 1 presents a proposal for a possible classification of the activities and housing functions.

This housing functional analysis helps define the requirements and ensures the satisfaction of a broad percentage of dwellers. This is important because, in general, it is no possible to know the future dwellers, or it is difficult to ask every a dweller about their needs and aspirations.

Table 1. Classification of activities and housing functions.

\begin{tabular}{|c|l|l|}
\hline Functions & \multicolumn{1}{|c|}{ System of Activities } & \multicolumn{1}{c|}{ Activity } \\
\hline Meal Preparation / Eating & $\begin{array}{l}\text { Meal Preparation } \\
\text { Meals (current or formal) } \\
\text { Housekeeping / pantry }\end{array}$ & $\begin{array}{l}\text { Storing and preserving food; Preparing food; } \\
\text { Cooking food; Washing and pack washer; } \\
\text { Setting the table and serving food; Eating; } \\
\text { General housekeeping }\end{array}$ \\
\hline Living / gathering & $\begin{array}{l}\text { family leisure } \\
\text { watching TV } \\
\text { receiving guests }\end{array}$ & $\begin{array}{l}\text { Chat, playing games, reading; Listening to } \\
\text { music; Watching TV; Serving appetizers / } \\
\text { drinks }\end{array}$ \\
\hline Sleeping / personal rest & $\begin{array}{l}\text { Sleeping / rest } \\
\text { Storage of personal clothing }\end{array}$ & $\begin{array}{l}\text { Sleeping (night or day); Resting; Reading / } \\
\text { watching TV; Dressing and undressing clothes; } \\
\text { Talking on the phone; Talking privately; Pack } \\
\text { up personal clothing }\end{array}$ \\
\hline Circulation & $\begin{array}{l}\text { Entry / exit of spaces } \\
\text { Communication / separation } \\
\text { of spaces }\end{array}$ & $\begin{array}{l}\text { Moving between compartments; } \\
\text { Separate compartments }\end{array}$ \\
\hline $\begin{array}{l}\text { Stay abroad } \\
\text { private }\end{array}$ & $\begin{array}{l}\text { Staying in the private outdoor } \\
\text { (in elevated or ground level) }\end{array}$ & $\begin{array}{l}\text { Resting and solarium; Caring for flowers and / } \\
\text { or animals; Being / outdoor leisure; Extending / } \\
\text { catching clothes }\end{array}$ \\
\hline Work & $\begin{array}{l}\text { Studying; Using personal computer; Playing } \\
\text { games, reading, listening to music, watching } \\
\text { TV }\end{array}$ \\
\hline working
\end{tabular}

\section{Occupation Typologies}

The functional analysis of the housing primarily aims to expose and characterize the main activities and to define typologies that can be coordinated, allowing to adapt the housing to family's needs according to their social and cultural dynamics. Considering the several types of occupation, the project conception o will be adapted to the different life experiences of the dwellers in order to meet the needs of each of them. Based on these life experiences, 
this study proposes five different typologies: living, sleeping, circulating, cultivating (mind, body, and earth), and working (Table 2).

The LIVING typology groups many differentiated activities and can be defined as the set of activities related to the preparation of meals, meetings, and leisure, in family or individually. These activities are mainly related with the available free time. The SLEEPING typology is mainly defined by the activity of sleeping/resting and is usually associated with other activities such as dressing/undressing, working, and personal entertainment. The CIRCULATION typology basically consists in entries and exits systems for spaces, communication, and separation of spaces and vertical access systems. The CULTIVATING typology consists of the private outdoor area, being the extension of some functions that take place within the housing, such as resting, leisure, or gardening/horticulture. Finally, the WORKING typology includes the work area, either private (office, creative space) or open to the public.

Table 2. Typologies of occupation according to the functional analysis of the housing use.

\begin{tabular}{|c|c|c|c|c|}
\hline LIVING & SLEEPING & CIRCULATION & CULTIVATING & WORKING \\
\hline A & B & C & D & $\mathbf{E}$ \\
\hline Meal preparation & $\begin{array}{l}\text { Sleeping / Personal } \\
\text { rest }\end{array}$ & Circulation & $\begin{array}{c}\text { Staying in private } \\
\text { outdoor }\end{array}$ & Working \\
\hline Meals & $\begin{array}{l}\text { Study / Children } \\
\text { recreation }\end{array}$ & $\begin{array}{c}\text { Entry and exit of } \\
\text { spaces }\end{array}$ & $\begin{array}{l}\text { Resting and } \\
\text { solarium }\end{array}$ & Servicing public \\
\hline Housekeeping & Housekeeping & $\begin{array}{l}\text { Communication and } \\
\text { separation of spaces }\end{array}$ & $\begin{array}{l}\text { Caring flowers } \\
\text { and/or animals }\end{array}$ & Creative space \\
\hline $\begin{array}{c}\text { Ironing / Washing } \\
\text { clothes }\end{array}$ & Working & Vertical accesses & Being outdoors & Office \\
\hline Receiving & $\begin{array}{c}\text { Reading / Watching } \\
\text { TV }\end{array}$ & Free Space & Leisure space & \\
\hline $\begin{array}{c}\text { Living / Gathering } \\
\text { (family leisure) }\end{array}$ & & & Clothes drying & \\
\hline
\end{tabular}

\section{Spatiofunctional Analysis}

LIVING typology is associated with the food preparation space, meal space, storage space (pantry), and also a space for laundry care (washing, drying, and ironing). This typology can also be associated with a space for living (sitting)/gathering, which ensures a more intensive interaction between all family members. According to Pedro (2001), the design of meal spaces must account for the size of the meal table, the width of the circulation tracks, and also the table position (centered or leaning against a wall). The existence of a meal space integrated in the kitchen allows the dining table to serve as support for various functions, such as food preparation or support element for the study of young people. 
With respect to the function living/gathering, this one mainly takes place in a common space, lounge or, alternatively, in a balcony, terrace, or backyard. This space should have good conditions for living together and a proper arrangement of furniture. The design of this space should account for the physical dimensions and the use of the furniture, as well as its arrangement and flexibility to assume other arrangements as necessary.

In the allocation of areas for sleeping/personal resting spaces, some aspects must be considered, such as the necessary furniture set for each activity system, circulation tracks, and frequent arrangements of the furniture. To design the sleeping/personal resting spaces, the main aspect to consider is the position of the beds, and, for each arrangement, the remaining and necessary furniture should be also considered. The circulation tracks must allow easy access to all points of the room. As an example, Table 3 presents the minimum dimensions and areas for sleeping spaces according to Pedro (2001). According to this author, the CIRCULATION typology includes entry/exit and communication/separation of spaces, with circulation tracks for access and separation between some compartments. To set the minimum dimensions, the physical dimensions, the use of furniture, and the free circulation areas must be considered.

Table 3. Minimum dimensions and areas for sleeping spaces (Pedro, 2001).

\begin{tabular}{|l|c|c|c|c|c|c|}
\hline \multicolumn{1}{|c|}{ Sleeping } & \multicolumn{2}{c|}{ Minimum } & \multicolumn{2}{c|}{ Recommended } & \multicolumn{2}{c|}{ Optimum } \\
\hline Double (couple) room & $2.60 \mathrm{~m}$ & $\mathrm{~A}=10.5 \mathrm{~m}^{2}$ & $2.90 \mathrm{~m}$ & $\mathrm{~A}=11.5 \mathrm{~m}^{2}$ & $3.30 \mathrm{~m}$ & $\mathrm{~A}=12.0 \mathrm{~m}^{2}$ \\
\hline Double room & $2.10 \mathrm{~m}$ & $\mathrm{~A}=9.0 \mathrm{~m}^{2}$ & $2.40 \mathrm{~m}$ & $\mathrm{~A}=10.0 \mathrm{~m}^{2}$ & $2.70 \mathrm{~m}$ & $\mathrm{~A}=11.0 \mathrm{~m}^{2}$ \\
\hline Single room & $2.10 \mathrm{~m}$ & $\mathrm{~A}=5.5 \mathrm{~m}^{2}$ & $2.40 \mathrm{~m}$ & $\mathrm{~A}=6.0 \mathrm{~m}^{2}$ & $2.70 \mathrm{~m}$ & $\mathrm{~A}=6.5 \mathrm{~m}^{2}$ \\
\hline
\end{tabular}

The CULTIVATING typology allows the permanence in private outer space, which can be in an elevated level or in the ground level. These spaces allow to develop several leisure activities, such as cultivating or planting flowers and hanging out the clothes. The minimum dimensions depend on the furniture used for different activities and vary by type of intended use.

The dedicated area to work, being private or public, includes an office area devoted to the study or use of computer, or an area devoted to trade, which is open to the public.

\section{STUDY AND APPLICATION OF A MODULAR CONSTRUCTION SYSTEM WITH CONTAINER MODULE}

The aim of this section is to present a proposal to develop a modular construction system based on shipping containers as modules, whose combination is easy to perform and with some degree of differentiation and/or customization between the modules. For this purpose, a diagram of modular typologies of occupation is presented. This diagram will admit changes related to the household, in order to create several housing types from the addition or subtraction of modules. This study of modular coordination is based on shipping containers, so the measurements of these elements will condition the size of the module.

In this study, the following two ISO models of containers are used (Figure 5): 40' HC and 20' $\mathrm{HC}$ (commercial designation). These containers are also designated by ISO as $1 \mathrm{AAA}$ and $1 \mathrm{CCC}$, respectively. The meaning of the terminology and the reasons to choose these containers were previously explained. 
The height of those containers $(2.71 \mathrm{~m})$, higher than the height of many other containers in the market, enables a minimum clear ceiling height of $2.40 \mathrm{~m}$ for housing (minimum requirement according to several urban construction codes). Table 4 presents the main geometrical characteristics of the referred containers. Another feature is that both referred containers are multiples of each other (Figure 6).

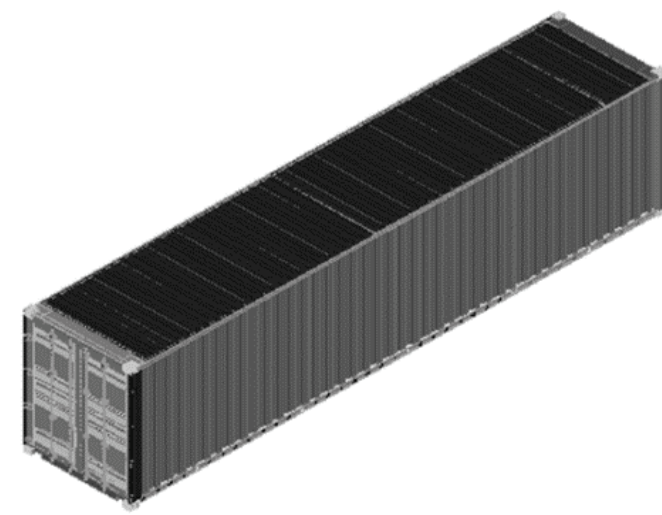

$40{ }^{\prime} \mathrm{HC}$

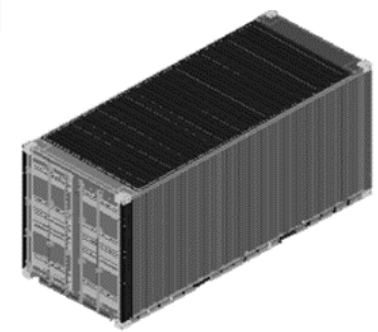

$20{ }^{\prime} \mathrm{HC}$

Figure 5. Containers $20^{\prime} \mathrm{HC}$ and $40^{\prime} \mathrm{HC}$.

Table 4. Geometrical characteristics of containers $20^{\prime} \mathrm{HC}$ and $40^{\prime} \mathrm{HC}$.

\begin{tabular}{|c|c|c|c|c|c|c|c|}
\hline \multirow{2}{*}{ Model } & \multicolumn{3}{|c|}{ External dimensions } & \multicolumn{2}{c|}{ Minimum internal dimensions } \\
\cline { 3 - 8 } & High & Width & Length & High & Width & Length \\
\cline { 3 - 8 } & {$[\mathrm{mm}]$} & {$[\mathrm{mm}]$} & {$[\mathrm{mm}]$} & {$[\mathrm{mm}]$} & {$[\mathrm{mm}]$} & {$[\mathrm{mm}]$} \\
\hline 1AAA & $40^{\prime} \mathrm{HC}$ & 2896 & 2438 & 12192 & 2655 & 2330 & 11998 \\
\hline 1CCC & $20{ }^{\prime} \mathrm{HC}$ & 2896 & 2438 & 6058 & 2655 & 2330 & 11998 \\
\hline
\end{tabular}
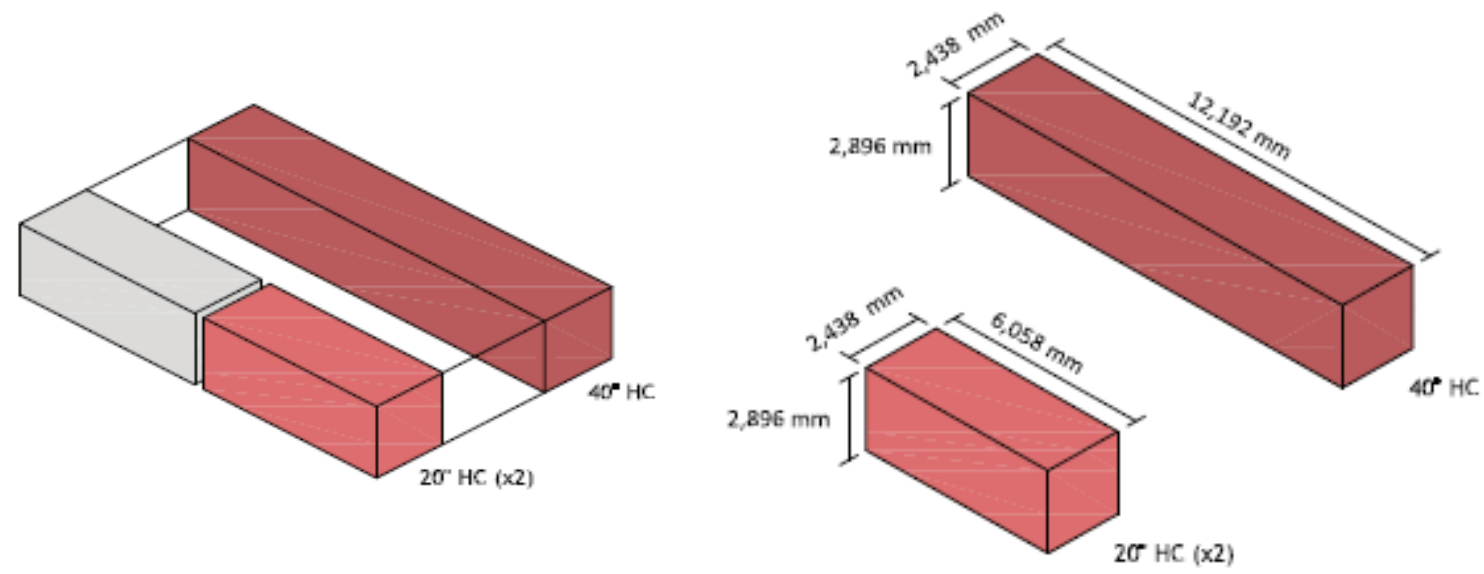

Figure 6. The modules (containers $20^{\prime} \mathrm{HC}$ and $40^{\prime} \mathrm{HC}$ ). 
As illustrated in Figure 7, the containers are composed by the front face (1), the face of the door (2), two sides (3), roof (4), and the base-structure (5).

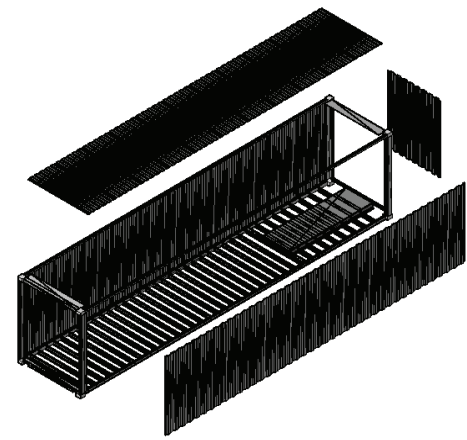

$40^{\prime} \mathrm{HC}$

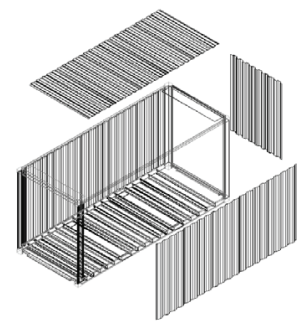

$20 ’ \mathrm{HC}$

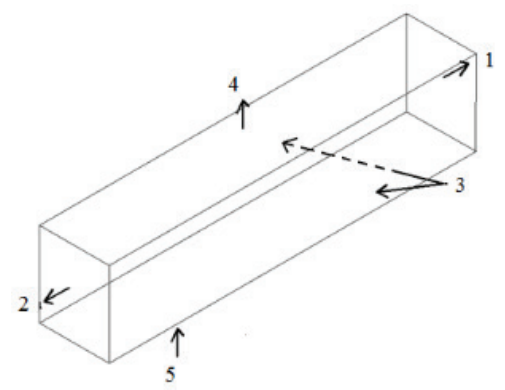

Figure 7. Containers composition.

The front face is composed by two trapezoidal sheets (jointed through welding) to form a panel welded to a frame, which constituted of several profiles: an upper front header, a lower square steel tube, two vertical corner posts, and four corner pieces.

The door face is composed by one frame, which includes a lower door sill made with a channel section, two vertical corner posts built with a channel shape in hot-rolled steel, and another one in cold formed steel welded together to form a hollow section, an upper door header composed by an inner "U," and an outer shape made of cold formed steel welded together to form a hollow section, four corner pieces, and secondary elements of the door locking devices.

Each door leaf includes a sheet welded to a frame with a locking device, two hinges, seals, and supports. The doors are usually removed and used as secondary construction elements.

The lateral faces are composed of an upper square steel tube and the side wall composed of several trapezoidal sheets held together by welding.

The roof consists of pressed steel sheets. Such sheets are not generally considered as structural element once ribs do not exist near the top side rail.

Containers also include many local strengthening plates. The terminology generally used to designate many of the elements follows ISO standards for container vocabulary.

\section{Modular Coordination of Container Construction System}

The modular coordination is mainly based on the application of a module (or multimodule) to create scaled and proportional relationships between the building components. In this study, the relationships between the dimensions of both containers $40^{\prime} \mathrm{HC}$ and $20^{\prime} \mathrm{HC}$ are investigated. Such relationships are represented in a simplified way in the modular grids shown in Fig. 8(a) and Fig. 8(b). 
The modular grid A represents the dimensions in plant view of the container $40^{\prime} \mathrm{HC}$ (repetitions of the module $12192 \times 2438 \mathrm{~mm}$ ), whereas the modular grid B represents the dimensions in plant view of the container $20^{\prime} \mathrm{HC}$ (repetitions of the module $6058 \times 2438 \mathrm{~mm}$ ). The relationship between these two modular grids is shown in Fig. 8(c) (modular grid A + B), where each module 40'HC "agrees" with two modules $20^{\prime} \mathrm{HC}$. This aspect reflects the multimodular relationship between the two types of containers. This multimodular relationship is very useful in projects with recycling containers, because it facilitates the flexibility of modular composition. It is also necessary to study the containers relationship when they are positioned perpendicularly or transversely, as shown in Fig. 9(a). By combining modular grids $\mathrm{C}$ and $\mathrm{A}$, it follows that, for each module $40^{\prime} \mathrm{HC}$, it is possible to position transversally five containers (Fig. 9(b) and Fig. 9(c)).

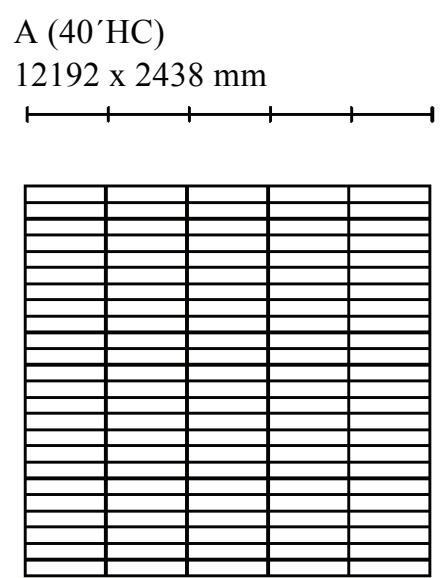

(a)
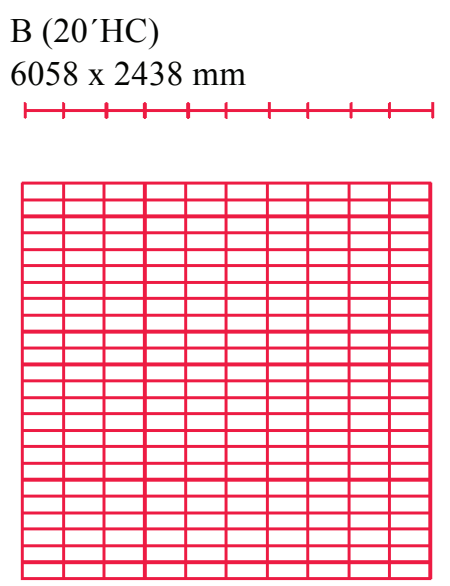

(b)
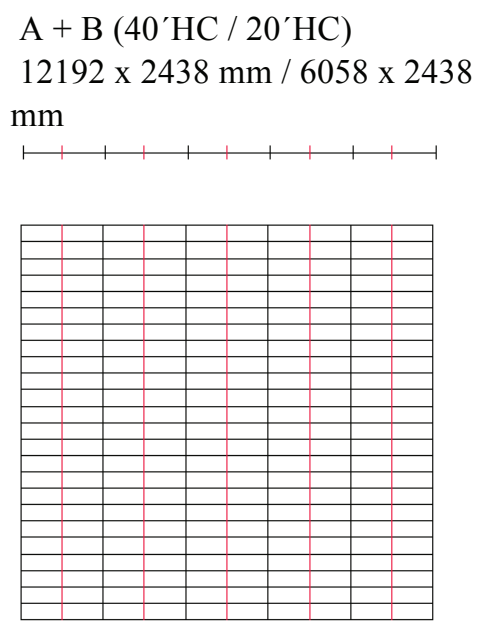

(c)

Figure 8. Modular grids A, B, and A + B.

C $\left(20^{\prime} \mathrm{HC} / 40^{\prime} \mathrm{HC}\right)$

Transversal

$2438 \times 2896 \mathrm{~mm}$

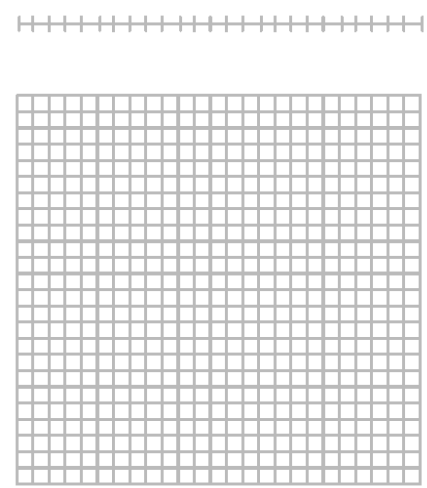

(a)

\begin{abstract}
$\mathbf{A}+\mathbf{C}\left(40^{\prime} \mathrm{HC}\right)$
Transversal relationship

12192 x $2438 \mathrm{~mm} / 2438$ × 2896

$\mathrm{mm}$
\end{abstract}

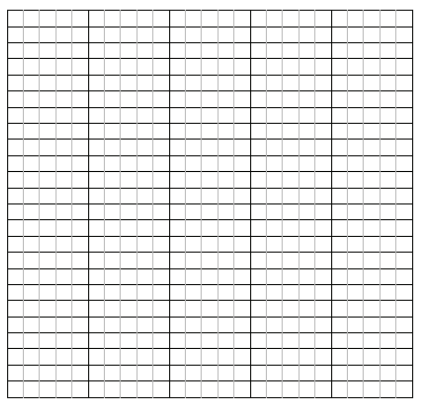

(b)

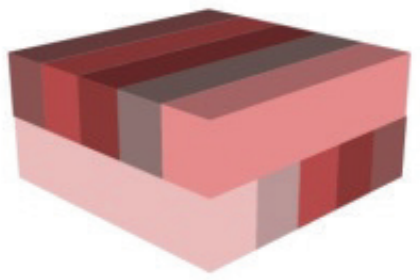

(c)

Figure 9. Modular grids $\mathrm{C}$ and $\mathrm{A}+\mathrm{C}$. 
Finally, in order to compare the three modular grids A, B, and C, they are assembled. The resulting modular grill $\mathrm{A}+\mathrm{B}+\mathrm{C}$ explains how the different grids are interrelated (Fig. 10(a)). The modular grid $\mathrm{A}+\mathrm{B}+\mathrm{C}$ becomes a tool to simplify the study of the modulation. This modular grid represents the several dimensional relationships between the shipping containers $20^{\prime} \mathrm{HC}$ and 40'HC (Fig. 10(b)).
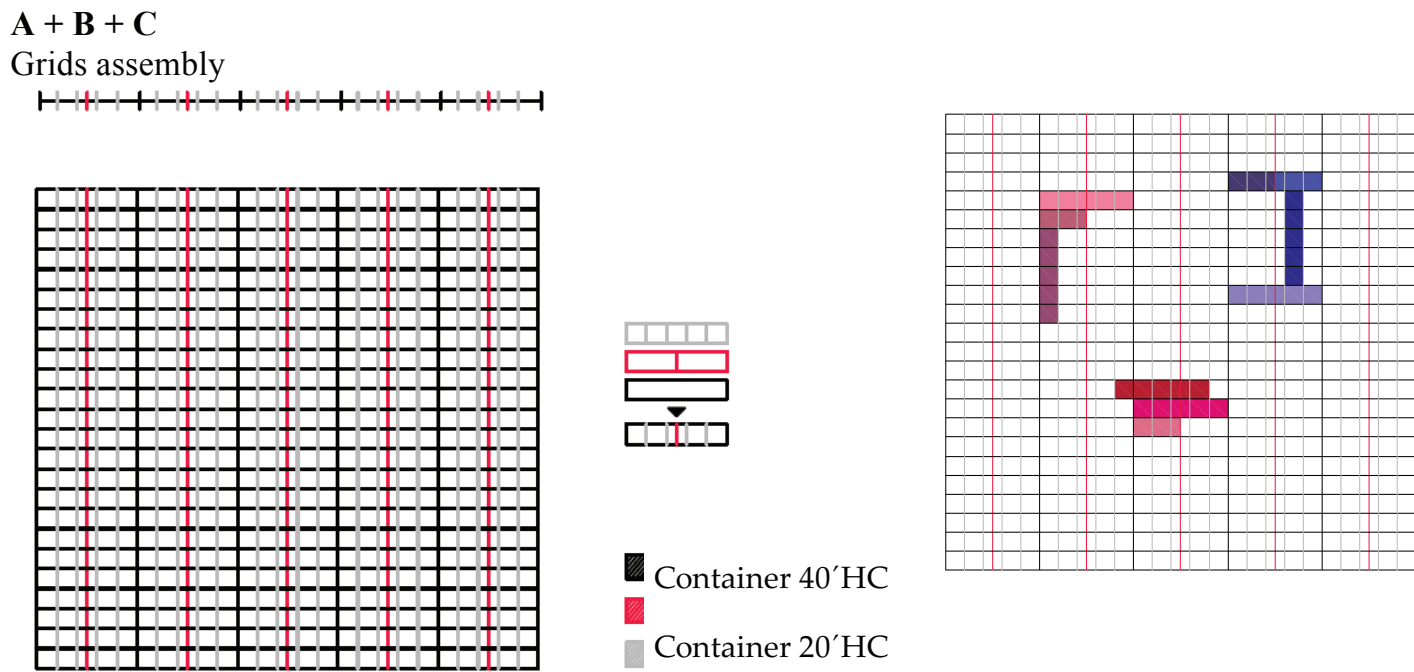

(a)

(b)

Figure 10. Modular grid A $+\mathrm{B}+\mathrm{C}$.

\section{Application of occupation typologies in modular design with containers}

Through the several typologies of modular occupation, the conception design can be adapted to the different experiences of the dwellers, in order to meet the needs of each of them. The five essential typologies related with the housing experience are based on physiological and social needs of the dweller, when alone or in group. These needs are living, sleeping, circulation, cultivating (mind, body, and earth), and working. For each typology, some variants are proposed in this article. These variants are based on both containers 40'HC (12 x $2.34 \times 2.71 \mathrm{~m}$, area $\left.28.08 \mathrm{~m}^{2}\right)$ and $20^{\prime} \mathrm{HC}\left(5.90 \times 2.34 \times 2.71 \mathrm{~m}\right.$, area $\left.13.81 \mathrm{~m}^{2}\right)$.

The LIVING typology is constituted by the entry area and respective hall, kitchen and eating area, and living room. Thus, this typology presents three variants (A1, A2, and A3) with different useful floor areas dedicated to each zone. The A1 variant is constituted by a shipping container $20^{\prime} \mathrm{HC}$ and includes hall, toilet (with no bath facilities), kitchen and eating area, and a small living room (which can also be used as a bedroom). Due to its small size and to the lack of bath facilities, this area cannot be considered as a fully living space. However, it can be used in coordination with the other typologies and variants. The A2 and A3 variants consist of shipping containers 40 'HC. The A2 variant includes hall, a storage space (and / or pantry), toilet (with no bath facilities), cooking and eating space with possible storage area, a living room, and balcony. The A3 variant is quite similar to A2, with bath facilities in the toilets and a broader living room. A3 variant does not incorporate a balcony. Figure 11 illustrates the three variants (A1, A2, and A3) of the LIVING typology.

The rooms' area, used mainly to rest, is part of the typology SLEEPING. This typology also presents three variants (B1, B2, and B3) to allow for the space coordination to be more flexible and diversified. Variant B1 is composed of the shipping container $20^{\prime} \mathrm{HC}$ and includes only one room (double or single) and sanitary installation. 
This variant can be used as a modular unit for the composition of spaces, such as university residences or hotels. When combined with one of the variants from typology LIVING, it becomes part of a dwelling that meets all the habitability requirements. Variants B2 and B3 consist of shipping containers 40'HC. The variant B2 includes a double and a single bedroom, both sharing the same sanitary installation, and also a small hall. The spaces can be reshaped as needed, accepting several furniture arrangements and other functions. Variant B3 includes a broader bedroom with a private bathroom. It also incorporates a vertical access to the upper floor, which allows to coordinate the modules vertically and/or to use roofs. The variants (B1, B2, and B3) of the SLEEPING typology are shown in Figure 12.
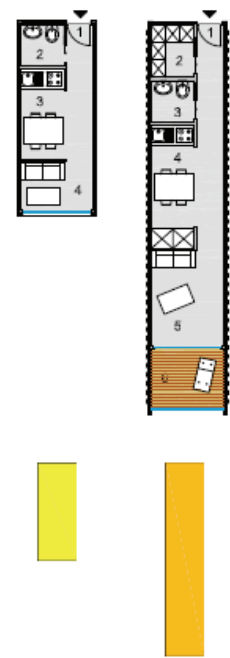

Al A2
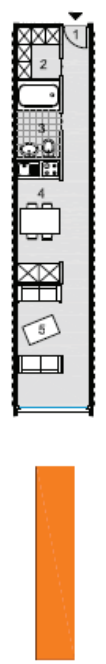

A3
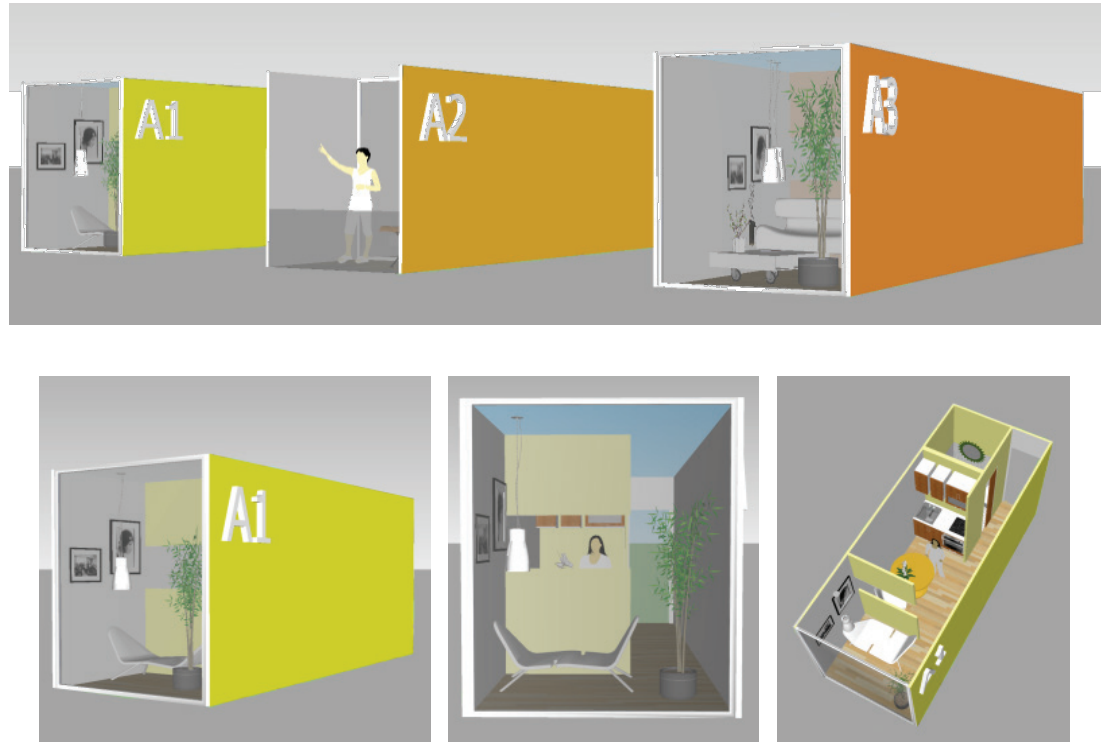

Figure 11. LIVING typology: variants A1, A2, and A3.
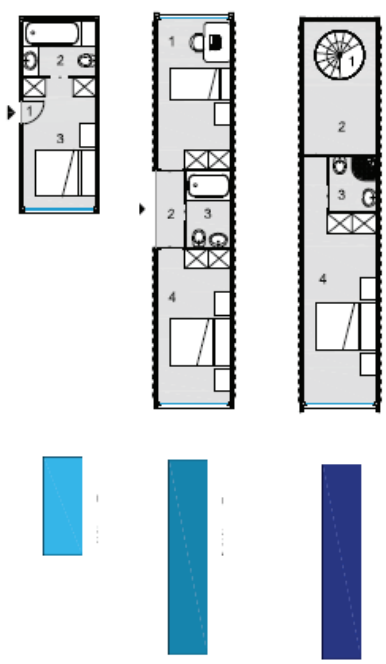

BI B2
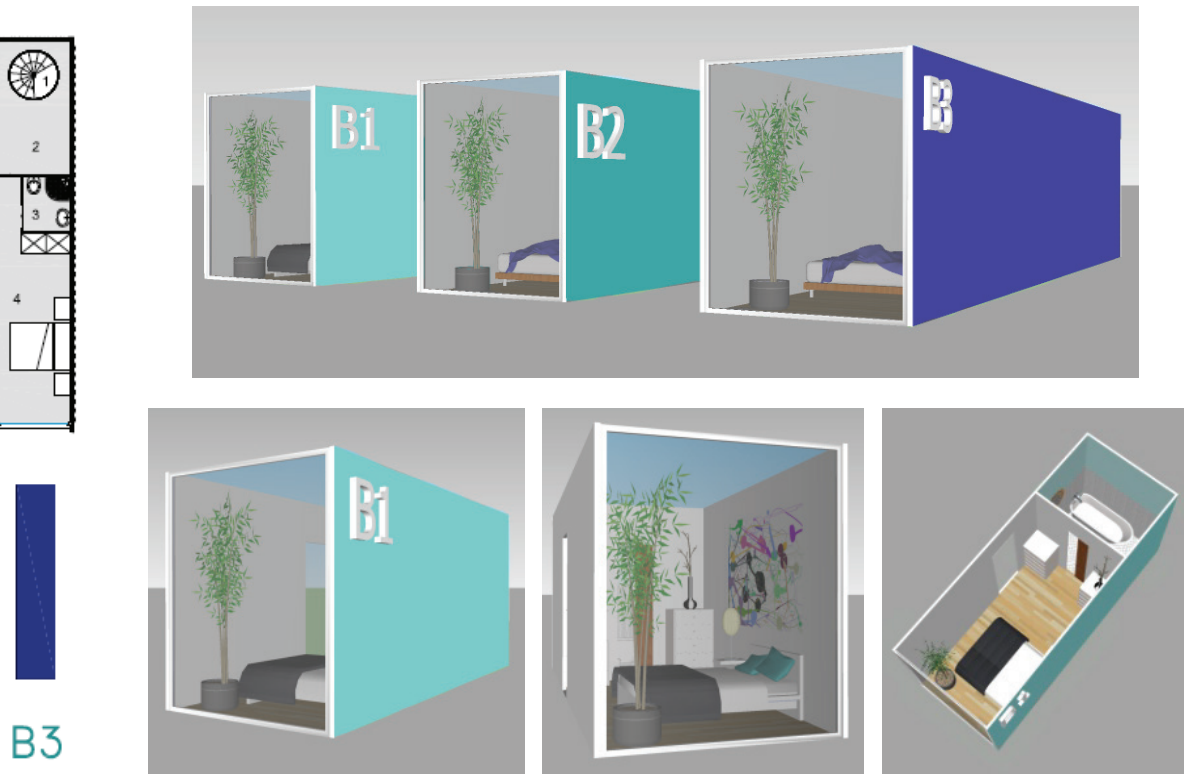

Figure 12. SLEEPING typology: variants B1, B2, and B3. 
The typology CIRCULATION is characterized as a transition space, being used as a free space with or without vertical accesses. The secondary function of these spaces is to facilitate the combination and coordination of other typological modules in modular combinations. This typology also presents three variants $(\mathrm{C} 1, \mathrm{C} 2$, and $\mathrm{C} 3)$. Variant $\mathrm{C} 1$, like the previous ones, is composed of a shipping container $20^{\prime} \mathrm{HC}$ and includes a free space and a vertical access (spiral staircase), which connects the various floors (if vertical modular coordination exists). Variant C2 is quite similar, although it uses shipping containers $40^{\prime} \mathrm{HC}$ and includes a balcony. Finally, variant $\mathrm{C} 3$ comprises a free space (in the whole area of the container). The variants of the CIRCULATION typology (C1, $\mathrm{C} 2$, and $\mathrm{C} 3$ ) are shown in Figure 13.
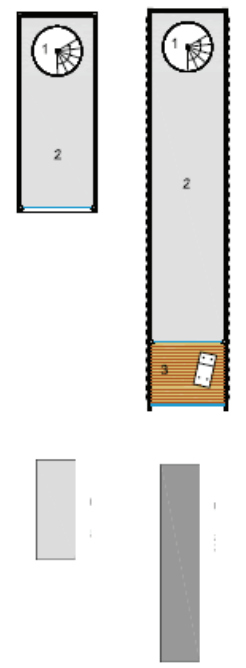

Cl
$\mathrm{C} 2$
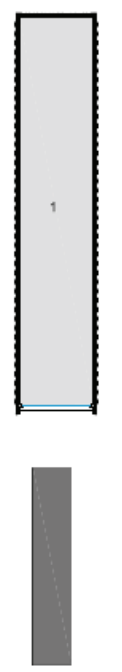

C3
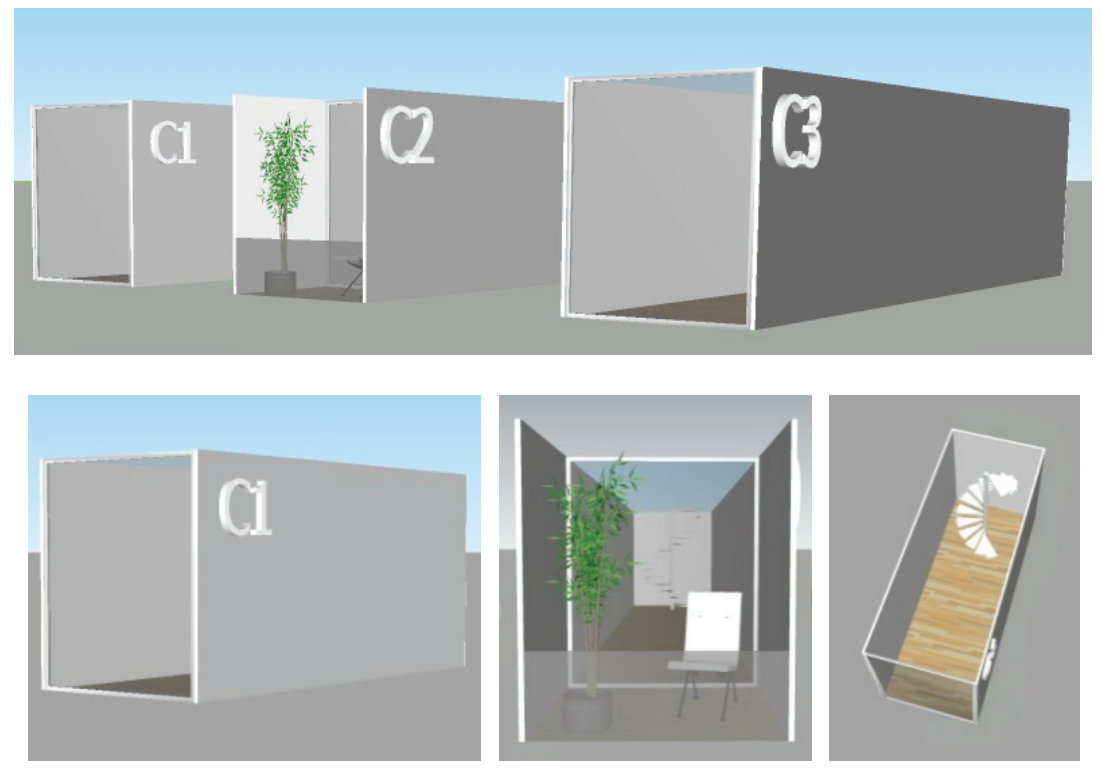

Figure 13. CIRCULATION typology: variants $\mathrm{C} 1, \mathrm{C} 2$, and $\mathrm{C} 3$.

The typology CULTIVATING is perhaps the broadest of all the typologies, which best stimulates the bodymind balance, as a healthy goal to be achieved by the dweller individually or in group. This typology is characterized by recreational areas and green spaces exposed outdoors, which promote living together with the cultivation of body, mind, and earth. The three variants (D1, D2, and D3) are multifunctional spaces, which can work as garden or backyard, as leisure and conviviality places, or even as an outdoor gym. The introduction of green modules makes the modular vertical coordination quite interesting regarding the architectural composition, such as buildings with vertical gardens. Variant D1 uses a shipping container $20^{\prime} \mathrm{HC}$ and provides a sort of winter garden (in the whole area of the container). It consists of a kind of grid that underpins mobile potted vegetation, which can be changed according to the dwellers. Variants D2 and D3 use shipping containers 40'HC and are quite similar to variant D1 with respect to their spatial constitution. They include a green area dedicated to a backyard or kitchen garden. They also include a deck zone to delimitate spaces, allowing to separate the green area of the living/leisure. Moreover, variant D3 includes a water mirror with aesthetic function. Figure 14 illustrates the three variants (D1, D2, and D3) of the CULTIVATING typology. 

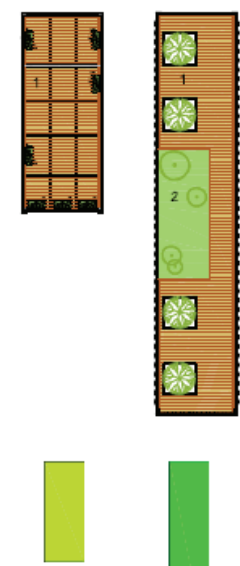

DI D2
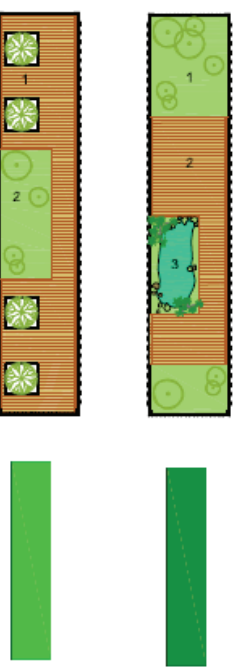

D3
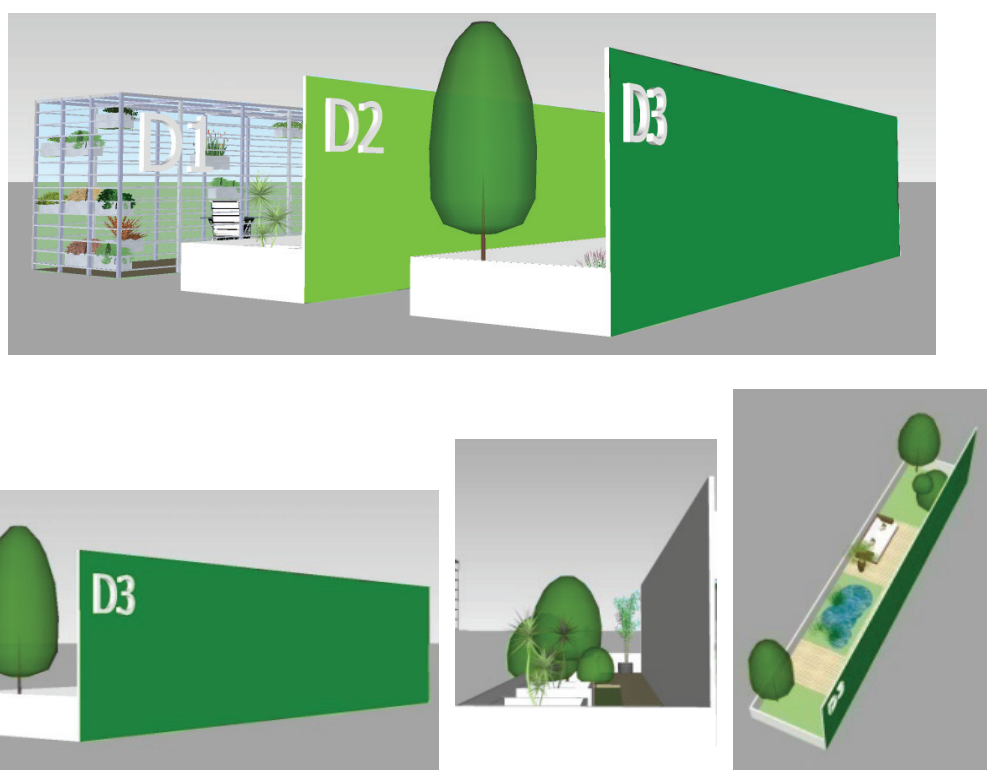

Figure 14. CULTIVATING typology: variants D1, D2, and D3.

The typology WORKING is a need of every human being. It is by working that the human being, in general, obtains the resources for food and for his own welfare. This typology is composed by open spaces equipped with sanitary facilities, in order to be adapted for any spatial organization for labor (commercial or other one). Only two variants E1 and E2 are presented. The first one uses the shipping container $20^{\prime} \mathrm{HC}$, while the second one uses the shipping container $40^{\prime} \mathrm{HC}$. These modules can be used alone, as well as combined with modules with housing characteristics. Variants E1 and E2 of the WORKING typology are shown in Figure 15.
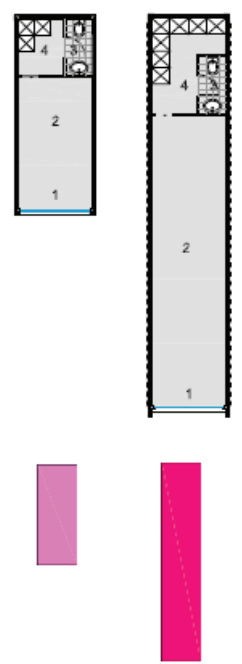

El E2
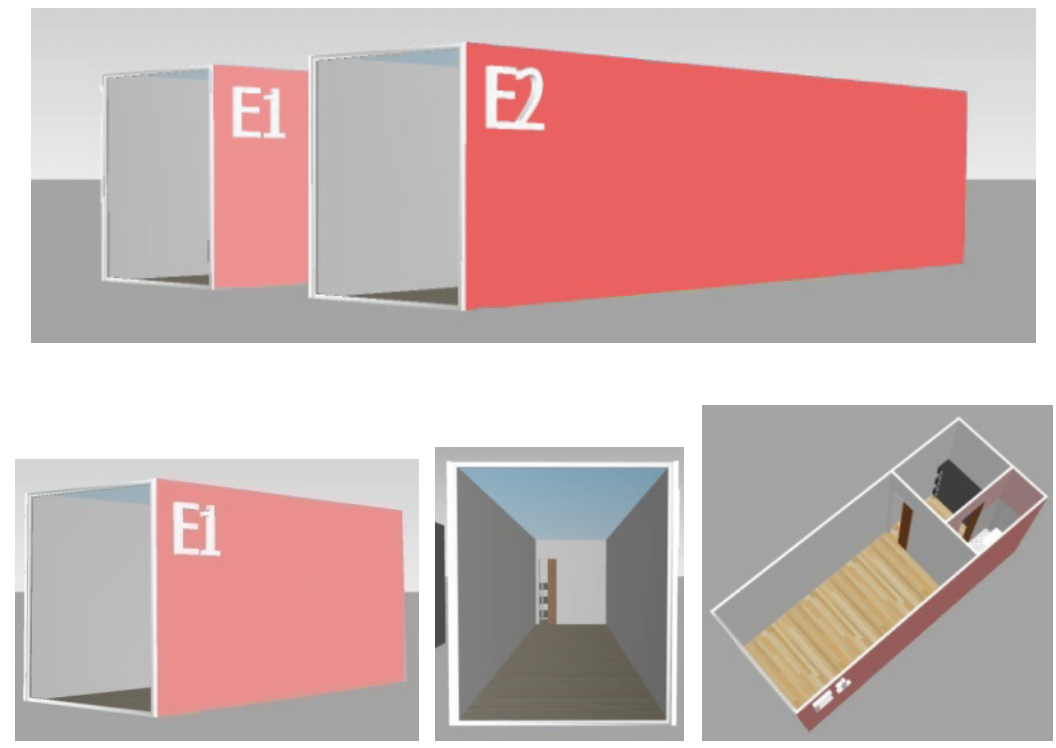

Figure 15. WORKING typology: variants E1 and E2. 


\section{Horizontal and Vertical Modular Coordination Design with Containers}

The modular coordination can be achieved in two Modular Reference Planes (MRP): in the horizontal and/or vertical plane. The horizontal modular coordination exists when the different modules are combined together and aligned in an imaginary plane parallel to the horizon. This plane is called the horizontal plane (Fig 16(a)). The vertical plane, perpendicular to the horizontal plan, establishes the modular vertical coordination. This coordination type is exactly aligned along the line of the direction of gravity, perpendicular to the horizon, as shown in Fig. 16(b).

This modular organization through two modular reference planes constitutes an additional tool to simplify the project and to rationalize the construction. It allows to ensure the dimensional coordination between the several parts and the whole.

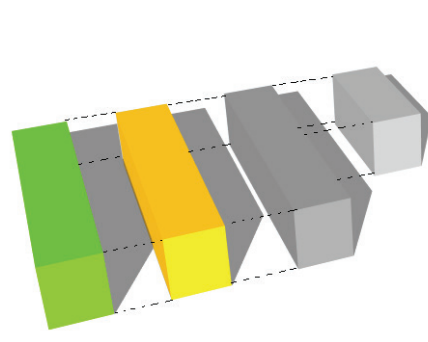

(a)
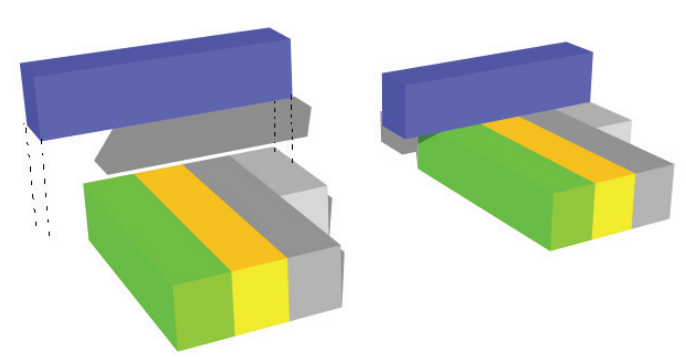

(b)

Figure 16. Horizontal and vertical modular coordination of modules.

The modular coordination of different occupancy typologies, as usually required by the dwellers, shows some problems for the vertical connections between modules. Therefore, before the construction phase, it is necessary to plan the whole project and select the required modules, their combination, as well as the openings in the facades, and the internal connections between modules (Figure 17). For example, in the case of multiple floors, the overlapping of circulation modules $\mathrm{C}$ must be considered, allowing access to the apartments through Living A modules and then arranging perpendicularly the combination with the other Sleeping B and Working E modules, among others. All this planning is necessary to achieve good results, in terms of both quality and economy of the construction.

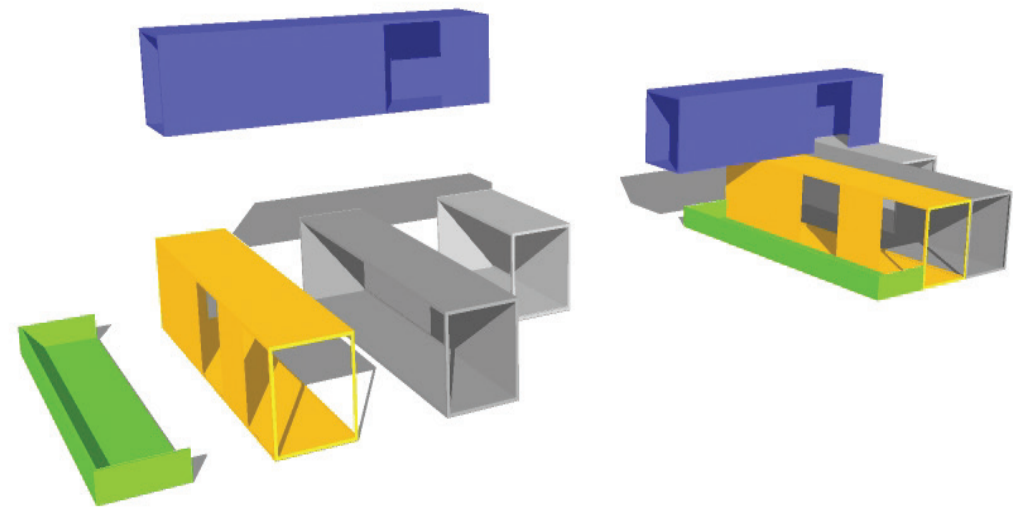

Figure 17. Example of openings and internal connections for a single-family house. 


\section{SOME CONSIDERATIONS ABOUT ADDITIONAL TECHNICAL DETAILS}

The refurbishment of shipping containers should be held in factories in order to ensure good quality control. The refurbishment process includes several works, such as cleaning and disinfection, openings, strengthening, connections, surfaces preparation, thermal and acoustic insulation, painting, and installation networks (Silva, 2010; Gomes 2010). All necessary details for the refurbishment of the containers should be incorporated in the project.

Finally, after the refurbishment, the containers are transported to the construction site to be assembled, according to the project plans. The prior preparation of the shipping containers allows for a faster and easy assembly of the modules.

\section{CONCLUSION}

Architectural projects thought to be built with refurbished shipping containers demonstrate that refurbished shipping containers, when used as modules, are allowed to be applied in many solutions and for a wide range of uses. With a formal and easily recognizable image, and with its inevitable modular character, refurbished shipping containers are allowed for multiplicity and conjugation to form elaborate and complex architectural compositions.

In order to rationalize the building construction with shipping containers, the theory of modular coordination was used in this article to develop some proposals to help find spaces and modular arrangements, and to contribute to flexible, aesthetic, and sustainable architectural spaces. In this way, the modular coordination becomes an essential tool to rationalize and simplify the development of the project, from the planning (paper) to the construction phase (ground).

The proposed spatial arrangements based on shipping containers, as presented in this paper, suggest a system of easy combination of modules with different degrees of differentiation and/or personalization between them, allowing to present several modular typologies of occupation. They allow for mutations and combinations to meet the household needs, making it possible to create several housing typologies based on the addition or subtraction of modules.

\section{REFERENCES}

Ahmad, T., Thaheem, M.J. \& Anwar, A. 2016. Developing a green-building design approach by selective use of systems and techniques. Architectural Engineering and Design Management. 12(1): 29-50.

Baldauf, A. 2004. Contribution to the implementation of modular coordination to the construction in Brazil. Master Thesis. University Federal of Rio Grande do Sul, Porto Alegre, Brazil. 146 p.

Bernardo, L.F.A., Pereira-de-Oliveira, L.A., Nepomuceno, M.C.S. \& Andrade, J.M.A. 2013. Use of Refurbished Shipping Containers for the Construction of Housing Buildings: Details for the Structural Project. Journal of Civil Engineering and Managemente. 19(5): 628-646.

Bitarafan, M., Hosseini, B.S., Abazarlou, S. \& Mahmoudzadeh, A. 2015. Selecting the optimal composition of architectural forms from the perspective of civil defense using AHP and IHWP methods. Architectural Engineering and Design Management. 11(2): 137-148.

Brandt, K.A. 2011. Plugging In: Reinterpreting the Traditional Housing Archetype Within a Community Using Shipping Containers. Master Thesis. University of North Carolina at Greensboro, USA. 93 p.

Castelo, J. 2008. Development of a conceptual model of industrialized light building system for steel buildings. Master Thesis. Faculty of Engineering of the University of Porto, Portugal, 278 p. 
Christensen, P. \& Worzala, E. 2010. Teaching Sustainability: Applying Studio Pedagogy to Develop an Alternative Post-Hurricane Housing Solution Using Surplus Shipping Containers. The Journal of Sustainable Real State. 43(1): 335-360.

Eilouti, B.H. 2009. Design knowledge recycling using precedent-based analysis and synthesis models. Design Studies. 30: 340-368.

European Commission, 2007. Accelerating the Development of the Sustainable Construction Market in Europe. Report of the taskforce on sustainable construction "A Lead Market Initiative for Europe".

Giriunas, K., Sezen, H. \& Dupaix, R.B. 2012. Evaluation, modeling, and analysis of shipping container building structures. Engineering Structures. 43: 48-57.

Gomes, M.J.M. 2010. Energy Analysis of Modular Constructions with Shipping Containers. Master Thesis. University of Beira Interior, Portugal. $174 \mathrm{p}$.

ISBU, 2009. Intermodal Steel Building Units and Container Homes. ISO Shipping Container Specifications/Materials.

Ismail, M., Al-Obaidi, K.M., Rahman, A.M.A. \& Ahmad, M.I. 2015. Container Architecture in the Hot-Humid Tropics: Potential and Constraints. Proceedings of the 4th ICERT 2015 International Conference on Environmental Research and Technology: Exploring the Frontiers in Environmental Science and Technology Research, Editors: Tow, T.T., Yusup, Y., Fadhlullah, W., Malaysia. pp. 142-149.

ISO 668:1995, 1995. Series 1 - Container shipping. Classification, dimensions and calculations. International Organization for Standardization, $6 \mathrm{p}$.

ISO 830:1999, 1999. Freight containers - Vocabulary. International Organization for Standardization, 40 p.

ISO 1496-1:1990, 1990. Series 1 - Container shipping. Specification and testing - Part 1: Containers for marine applications in use. International Organization for Standardization, $24 \mathrm{p}$.

ISO 3874:1997, 1997. Series 1 - Container shipping. Handling and safety. International Organization for Standardization, $29 \mathrm{p}$.

Lourenço, D.T. 2010. Constitution and Elastic Behavior Analysis of a Commercial Shipping Container. Master Thesis. University of Beira Interior, Portugal. 142 p.

Lun, Y.H.V. 2011. Green management practices and firm performance: A case of container terminal. Resources, Conservation and Recycling. 55(6): 559-566.

Marques, A.R.A. 2011. Study of Modular Coordination in Recycling Containers Projects. Master Thesis. University of Beira Interior, Portugal. $144 \mathrm{p}$.

Murdock, J. 2009. Now shipping to a site near you: Cargo container offices. Architectural Record. 197(10): 34.

NBR 5731, 1982. Coordenação modular da construção: terminologia (Modular coordination of construction: terminology). Associação Brasileira de Normas Técnicas, Brazil. (in Portuguese).

Nunes, N.C.G. 2009. Exploitation of shipping containers for housing. Master Thesis. University of Beira Interior, Portugal. $76 \mathrm{p}$.

Parasonis, J., Keizikas, A. \& Kalibatiene, D. 2012. The relationship between the shape of a building and its energy performance. Architectural Engineering and Design Management. 8(4): 246-256.

Pedro, J. 2001. Programa Habitacional: Habitação, 4a Edição, Laboratório Nacional de Engenharia Civil Informação Técnica Arquitetura ITA 5, Lisbon, Portugal. (in Portuguese).

Pisinger, D. 2002. Heuristics for the container loading problem. European Journal of Operational Research. 141(2): 382-392. 
Robinson, A. \& Swindells, T. 2012. Customized Container Architecture. ACSA Fall Conference 2012. pp. 6469.

Santisi, J. 2010. Shipped \& delivered: Houses from shipping containers hit the U.S. E 21(2), 44(2).

Silva, R.D.F. 2010. Construction with refurbished shipping containers: Study case. Master Thesis. University of Beira Interior, Portugal. 206 p.

Slessor, C. 2007. Remake, remodel: old shipping containers are inventively cannibalized to create a focus for play. The Architectural Review. 222(1330), 82(2).

Vijayalaxmi, J. 2010. Towards sustainable architecture - A case with Greentainer. Local Environment: The International Journal of Justice. 15(3): 245-259.

Volker, L., Lauche, K., Heintz, J. L. \& Jonge, H. 2008. Deciding about design quality: design perception during a European tendering procedure. Design Studies. 29(4): 387-409.

Webb, M. 2006. Container art: Shigeru Ban's Inventive Yet Frugal Nomadic Museum Berths on the Santa Monica Beachfront. Architectural Review. 219(1311): 48-53.

Zechmeister, D. 2005. Study for the standardization of dimensions of structural masonry units in Brazil by using modular coordination. Master Thesis. University Federal of Rio Grande do Sul, Porto Alegre, Brazil. 161 p. 